\title{
Auxerre. Études archéologiques de la façade ouest et dans les combles de la cathédrale Saint-Étienne (septembre 2002)
}

\section{Heike Hansen}

\section{(2) OpenEdition}

Journals

Édition électronique

URL : https://journals.openedition.org/cem/2942

DOI : $10.4000 /$ cem.2942

ISSN : 1954-3093

Éditeur

Centre d'études médiévales Saint-Germain d'Auxerre

Édition imprimée

Date de publication : 15 août 2003

ISSN : 1623-5770

Référence électronique

Heike Hansen, « Auxerre. Études archéologiques de la façade ouest et dans les combles de la cathédrale Saint-Étienne (septembre 2002) 》, Bulletin du centre d'études médiévales d'Auxerre I BUCEMA [En ligne], 7 | 2003, mis en ligne le 19 octobre 2007, consulté le 22 septembre 2022. URL : http:// journals.openedition.org/cem/2942; DOI : https://doi.org/10.4000/cem.2942

Ce document a été généré automatiquement le 22 septembre 2022.

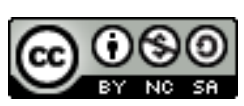

Creative Commons - Attribution - Pas d'Utilisation Commerciale - Partage dans les Mêmes Conditions 4.0 International - CC BY-NC-SA 4.0

https://creativecommons.org/licenses/by-nc-sa/4.0/ 


\title{
Auxerre. Études archéologiques de la façade ouest et dans les combles de la cathédrale Saint-Étienne (septembre 2002)
}

\author{
Heike Hansen
}

1 Dans le cadre de la restauration de la cathédrale d'Auxerre, effectuée avec la collaboration du conseil scientifique, Dieter Kimpel, membre du conseil et historien d'art, a proposé la collaboration de l'Institut d'Histoire de l'Architecture de l'Université de Stuttgart, dont il est le professeur titulaire.

2 La collaboration consiste à mener des recherches archéologiques soit en même temps que les travaux de restauration, tout en prenant avantage des échafaudages existants ou mis en place par la Ville d'Auxerre ${ }^{1}$, soit précédemment. La préparation, la mise au point et l'exploitation des dessins seront effectuées à Stuttgart. La version électronique des résultats paraîtra dans une phase ultérieure.

3 L'objectif principal des travaux a été défini en collaboration avec le conseil scientifique. Il consiste à dresser des relevés exacts des cinq portails de la façade occidentale et des croisillons pour donner un compte rendu de l'état de leur conservation, de leur matériau, de leur rapport avec l'architecture des façades et de leur chronologie relative. Les résultats pourront servir de données de base, bien sûr, pour la restauration de la cathédrale et aussi pour une étude future des sculptures des portails ; Peter Kurmann s'en chargera. Parallèlement, une partie de l'équipe s'est occupée et s'occupera du relevé des données d'autres parties de l'édifice dans la mesure où elles seront accessibles.

4 La première campagne a donc eu lieu en septembre 2002 sous la conduite de Heike Hansen, architecte spécialisée en archéologie monumentale. Son équipe, composée de trois autres archéologues/architectes (Bauforscher) et dix étudiants en architecture, a été divisée en deux groupes. 
5 1. Le groupe principal composé de trois architectes et cinq étudiants s'est occupé de la façade occidentale, surtout du portail central et du portail nord, à l'extérieur comme à l'intérieur. À partir d'un système de référence établi par les architectes, le groupe a principalement travaillé avec des moyens conventionnels - des cordes, fils à plomb, etc. Cette première étape a conduit à l'élaboration des vues extérieures des deux portails, d'un plan au niveau des niches d'ébrasement, d'une coupe longitudinale du portail nord ainsi que de dessins de détails. Tous ces relevés ont été réalisés à un très haut degré de précision et contiennent des observations supplémentaires, par exemple sur le remplacement de matériaux endommagés.

6 Ces travaux seront poursuivis en avril 2003. Ils porteront sur des secteurs d'accès malaisé et techniquement difficiles à mesurer, à savoir les archivoltes. Leurs mesures seront relevées selon la méthode électronique du tachéomètre et complèteront les plans inachevés des premiers travaux.

7 Jusqu'ici, les études des deux portails ont pu confirmer et préciser la chronologie de la construction des différentes parties proposée par Ursula Quednau ${ }^{2}$. En effet, les données nous informent sur les liens entre les différentes étapes de construction de la cathédrale. Nous avons effectué également des observations techniques. Les dais des niches du portail central étaient supportés par des colonnettes ; dans les ébrasements, un changement de plan dans les niches extérieures pourrait indiquer une modification du programme iconographique, puisque le premier projet ne comportait que dix grandes niches, un nombre insuffisant pour les douze statues des apôtres.

8 2. L'architecte Stefan King, spécialiste en charpentes historiques, a dirigé la deuxième équipe composée de cinq étudiants. Ils ont étudié les combles. Les travaux de restauration des toits étant en cours, l'observation a englobé la charpente de la nef maîtresse et du transept. La construction au-dessus de la croisée, les charpentes des bas-côtés et celles de la tour sud ont toutefois été exclues. La charpente de la tour sud est particulièrement intéressante puisqu'il s'agit d'une couverture provisoire mais médiévale dont la conservation s'impose. L'ordre des travaux a suivi les impératifs de l'urgence puisque la restauration de la charpente au-dessus de la nef maitresse était déjà en cours (cf. ce volume p. 15-19).

9 En ce qui concerne la construction de la toiture ainsi que ses détails techniques, l'équipe a d'abord rapidement tracé à l'aide du tachéomètre un plan général à l'échelle 1:50. Ensuite, six coupes transversales ont été établies à l'échelle 1:20. Cela a permis de distinguer plusieurs étapes de construction en accord avec les études dendrochronologiques de 1999. La chronologie relative de la toiture est aussi importante pour les parties maçonnées de la nef et du transept puisqu'elle fournit un terminus ante quem pour leur achèvement respectif.

10 En avril 2003, les deux groupes seront composés à peu près des mêmes chercheurs. Ils pourront donc poursuivre les travaux de façon coordonnée. Les résultats détaillés des recherches seront publiés après l'achèvement des études sur les combles, les portails et les autres parties de la cathédrale. Ils seront jumelés en partie aux résultats de la recherche du conseil scientifique de 2001. 


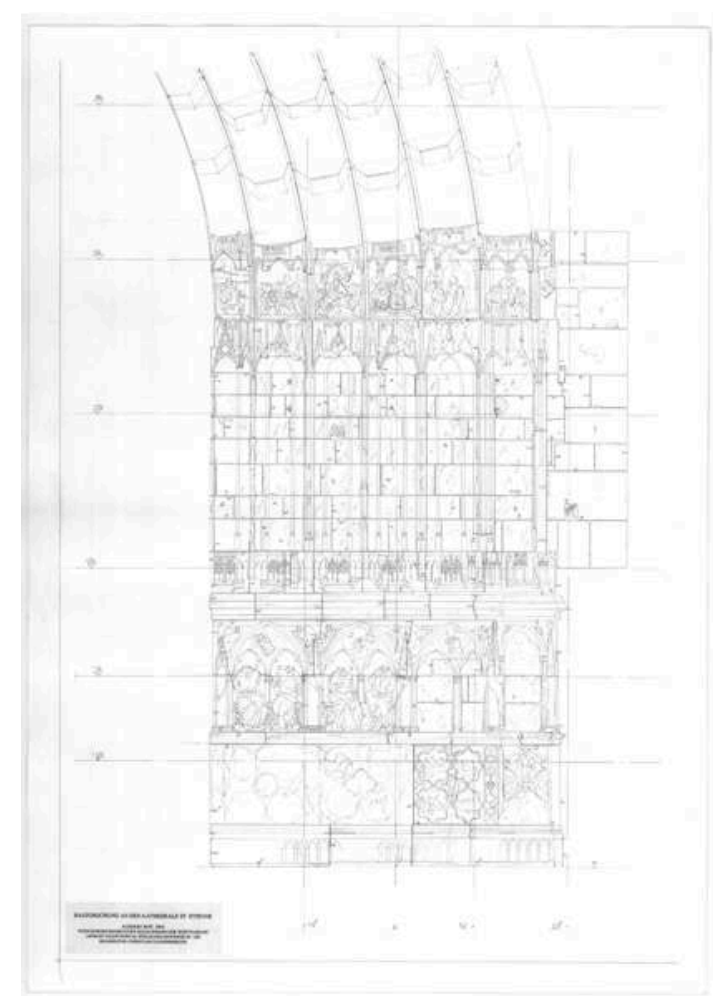

Auxerre, cathédrale Saint-Étienne, façade ouest - portail central, ébrasement sud (dessin H. Hansen université de Stuttgart).

\section{NOTES}

1.La mise à disposition de logements par la Ville d'Auxerre et la collaboration du CEM ont permis à l'équipe de jouir d'excellentes conditions de travail. Qu'ils en soient remerciés.

2.U. QUEDNAU, Die Westportale der Kathedrale von Auxerre, Wiesbaden, 1979.

\section{INDEX}

Mots-clés : cathédrale, Saint-Etienne d'Auxerre 